\title{
Research on Control-Oriented Modeling for Turbocharged SI and DI Gasoline Engines
}

\author{
Feitie Zhang, ${ }^{1}$ Shoudao Huang, ${ }^{2}$ Xuelong Li, ${ }^{3}$ and Fengjin Guan ${ }^{3}$ \\ ${ }^{1}$ College of Mechanical and Vehicle Engineering, Hunan University, Changsha 410082, China \\ ${ }^{2}$ College of Electrical and Information Engineering, Hunan University, Changsha 410082, China \\ ${ }^{3}$ Lifan Passenger Vehicle Company Limited, Chongqing 401122, China
}

Correspondence should be addressed to Shoudao Huang; shoudaohuang@tom.com

Received 9 January 2015; Accepted 26 February 2015

Academic Editor: Ming Huo

Copyright (C) 2015 Feitie Zhang et al. This is an open access article distributed under the Creative Commons Attribution License, which permits unrestricted use, distribution, and reproduction in any medium, provided the original work is properly cited.

\begin{abstract}
In order to analyze system performance and develop model-based control algorithms for turbocharged spark ignition and direct injection (SIDI) gasoline engines, a control oriented mean value model is developed and validated. The model is constructed based on theoretical analysis for the different components, including the compressor, turbine, air filter, intercooler, throttle, manifold, and combustion chamber. Compressor mass flow and efficiency are modeled as parameterized functions. A standard nozzle model is used to approximate the mass flow through the turbine, and the turbine efficiency is modeled as a function of blade speed ratio (BSR). The air filter is modeled as a tube for capturing its pressure drop feature. The effectiveness number of transfer units (NTU) modeling method is utilized for the intercooler. The throttle model consists of the standard nozzle model with an effective area regressed to throttle position. Manifolds are modeled for their dynamically varying pressure state. For the cylinder, the air mass flow into cylinders, fuel mass, torque, and exhaust temperature are modeled. Compared to the conventional lookup table approach, transient dynamics error can be improved significantly through using the model from this work.
\end{abstract}

\section{Introduction}

With the development of advanced combustion gasoline engines under Chinese intellectual property, advanced combustion engines are becoming an important research focus [1-3]. The path for improving the engine performance is to utilize advanced technologies such as turbocharging and direct injection and use advanced combustion concepts like stratified combustion and homogenous charge compression ignition (HCCI). With the increasing complexity of engine systems, control of engine is becoming a complex task. Thus, dynamic simulation models and model-based designs are increasingly used for designing and optimizing engine control strategies. The objective of this paper is to develop a mean value engine model which describes properties of spark ignition and direct injection (SIDI) engines.

The reference [4] constructed turbocharger models which focused on compressor flow rate by a curve fitting method. A component based modeling methodology [5] was utilized for developing the models for the compressor efficiency, compressor flow, and turbine flow. A simple model for the gas exchange process in diesel engine was developed in [6]. Based on thermodynamic analysis of compressor stage, a novel model-based approach was developed to predict the compressor behavior [7] which overcame the sparse nature of available compressor maps and characterized the flow and efficiency outputs of centrifugal compressors. Model predictive control was presented to coordinate throttle and turbocharger wastegate actuation for engine airflow and boost pressure control [8]. The model utilized the mass equation along with an isothermal manifold assumption. In order to design a controller for regulating speed of diesel engine, the nonlinear model was linearized and represented in a state-space form [9]. Reference [10] presented a controloriented model for predicting major turbine variables in a turbocharged spark ignition engine. In the model, the turbine was simulated as a two-nozzle chamber.

In this paper, a complete mean value model is presented including compressor, turbine, air filter, intercooler, manifold, throttle, and cylinder. The proposed submodels 


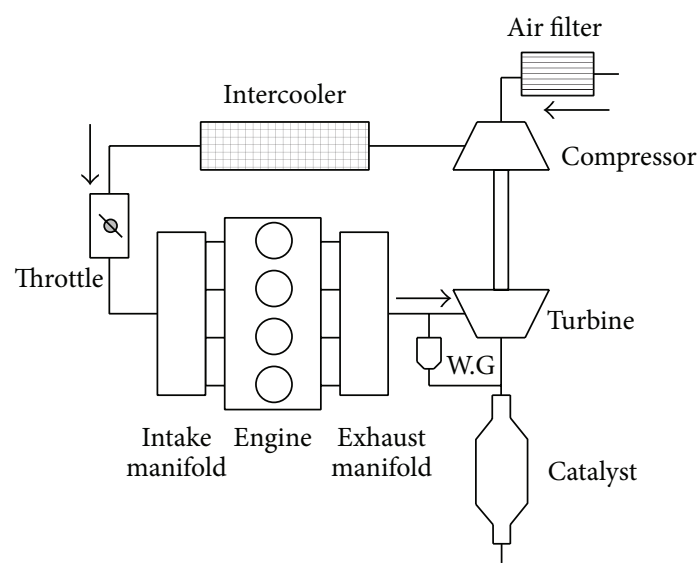

FIGURE 1: Sketch of the turbocharged SIDI engine.

capture key features of their corresponding component. All submodels are verified through the experimental data collected from a four-cylinder SIDI engine. Compressor and turbine models are developed as parameterized functions to describe the performance. The air filter is modeled as a simple pressure drop. The intercooler is modeled for its effect on intake temperature. The throttle is modeled to capture its flow rate. The manifolds are modeled with their pressure dynamics. For the cylinders, air mass flow into cylinders, fuel mass, and torque and exhaust temperature are modeled.

\section{Engine Overview}

The sketch of the turbocharged SIDI engine is displayed in Figure 1. The components to be modeled include compressor, turbine, air filter, intercooler, manifolds, throttle, and cylinders. Ambient air filtered through air filter is boosted by compressor. The boosted air is cooled down by intercooler and then flows into cylinder through throttle and intake manifold. A specified amount of fuel is injected into cylinder according to the mass of air. After combustion, the majority of exhaust gas exits, passing through the turbine and generating power for the compressor. The rest of the exhaust gas flows out through wastegate depending on the wastegate position. After being treated in the catalyst, exhaust gas returns back to the environment.

The specifications of the SIDI engine are shown in Table 1.

\section{Modeling}

3.1. Compressor. In order to supply the cylinder with air of high density, compressor pressurizes the air and directs it to the intake manifold. Compressor maps are usually described by corrected compressor mass flow, expansion ratio, modeled efficiency lines, and modeled speed lines. A compressor model should include the features from the map. In this paper, the compressor model consists of two submodels for compressor mass flow and compressor efficiency.
TABLE 1: Engine specifications.

\begin{tabular}{lcc}
\hline Specification & Value & Unit \\
\hline Displacement volume & 2 & Liter \\
Number of cylinders & 4 & - \\
Bore diameter & 86 & $\mathrm{~mm}$ \\
Stroke length & 86 & $\mathrm{~mm}$ \\
Compression ratio & 10.75 & - \\
Maximum torque & $340 @ 3500 \mathrm{rpm}$ & $\mathrm{N} \cdot \mathrm{m}$ \\
Maximum power & $178 @ 5500 \mathrm{rpm}$ & $\mathrm{Kw}$ \\
\hline
\end{tabular}

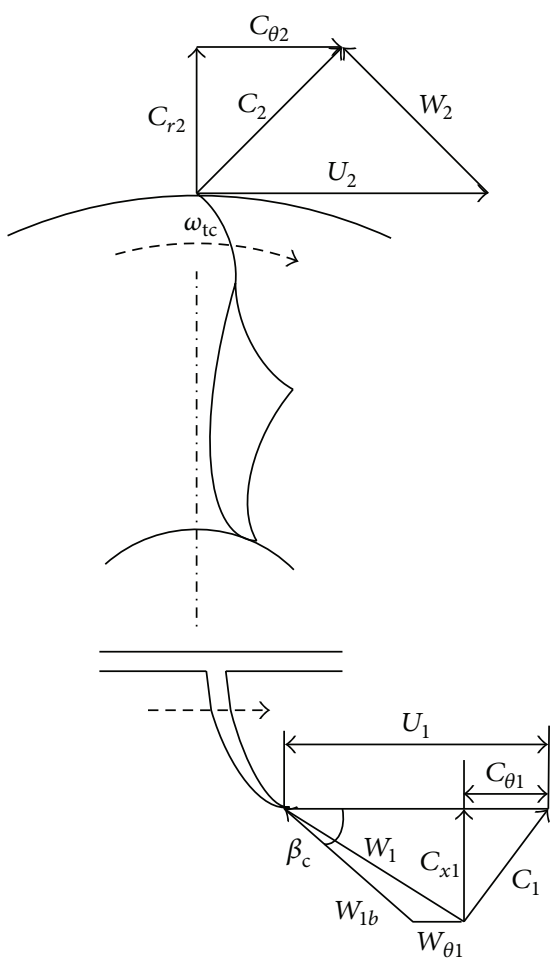

FIGURE 2: Velocity triangles of impeller eye and tip.

Based on analysis of specific energy transfer of compressor [11], Figure 2 shows the velocity triangles at the impeller eye and tip of the compressor with prewhirl:

$C_{1}$ : absolute velocity of air at impeller eye (inducer),

$C_{x 1}$ : axial component of $C_{1}$,

$C_{\theta 1}$ : tangential component of $C_{1}$,

$U_{1}$ : tangential component of blade tip speed,

$W_{1}$ : air velocity relative to blade (impeller eye),

$W_{1 b}$ : optimal value of $W_{1}$,

$W_{\theta 1}$ : destruction of tangential component of $W_{1}$,

$\beta_{c}$ : optimal angle,

$U_{2}$ : impeller tip speed,

$C_{2}$ : absolute velocity of air leaving impeller tip,

$C_{r 2}$ : radial component of $C_{2}$,

$C_{\theta 2}$ : tangential component of $C_{2}$, 
$W_{2}$ : air velocity relative to blade (tip),

$\omega_{t c}$ : turbo revolution speed.

According to geometrical relationships in Figure 2,

$$
W_{\theta 1}=U_{1}-C_{\theta 1}-\frac{C_{x 1}}{\tan \beta_{c}}
$$

Assuming turbocharger compressors without stationary prewhirl, the air approaching the impeller does not include a tangential component; that is, $C_{\theta 1}=0$.

Thus, (1) is rewritten as

$$
\begin{gathered}
W_{\theta 1}=U_{1}-\frac{C_{x 1}}{\tan \beta_{c}}=\omega_{t c} r_{c 1}-\frac{C_{x 1}}{\tan \beta_{c}} \\
C_{x 1}=C_{1}=\frac{\phi_{c}}{\rho_{c} A_{c}},
\end{gathered}
$$

where $\phi_{c}$ is inlet mass flow, $A_{c}$ is the inlet inducer crosssectional area, $\rho_{c}$ is air static density, and $r_{c 1}$ is inlet radius of impeller.

As the air adapts to the blade direction, the kinetic energy associated with the tangential component $W_{\theta 1}$ is destroyed. Thus, the incidence loss is given by

$$
h_{\mathrm{inc}}=\frac{W_{\theta 1}^{2}}{2} .
$$

From (2) and (4), (5) is derived:

$$
h_{\mathrm{inc}}=\frac{1}{2}\left(\omega_{t c} r_{c 1}-\frac{\phi_{c}}{\rho_{c} A_{c} \tan \beta_{c}}\right)^{2} .
$$

According to [11], the loss of useful energy due to friction is given by

$$
h_{\text {fric }}=\delta_{c} \phi_{c}^{2}
$$

where $\delta_{c}$ is an empirical constant.

Applying the Euler turbine equation and assuming $C_{\theta 1} r_{c 1} \ll C_{\theta 2} r_{c 2}$, the change of air angular momentum is given by

$$
h_{\text {total }}=\omega_{t c}\left(r_{c 2} C_{\theta 2}-r_{c 1} C_{\theta 1}\right)=\left(\omega_{t c} r_{c 2}\right)^{2},
$$

where $r_{c 2}$ is outlet radius of impeller.

The specific energy for isentropic compression is given by

$$
\Delta h_{c}=h_{\text {total }}-h_{\text {inc }}-h_{\text {fric }} .
$$

Substituting (5), (6), and (7) into (8),

$$
\Delta h_{c}=\left(\omega_{t c} r_{c 2}\right)^{2}-\frac{1}{2}\left(\omega_{t c} r_{c 1}-\frac{\phi_{c}}{\rho_{c} A_{c} \tan \beta_{c}}\right)^{2}-\delta_{c} \phi_{c}^{2} .
$$

The amount of energy required by the adiabatic compression process is given by

$$
\Delta h_{c}=C_{p} T_{\text {cin }}\left(\frac{p_{\text {cout }}}{p_{\text {cin }}}\right)^{1-1 / \gamma_{c}}
$$

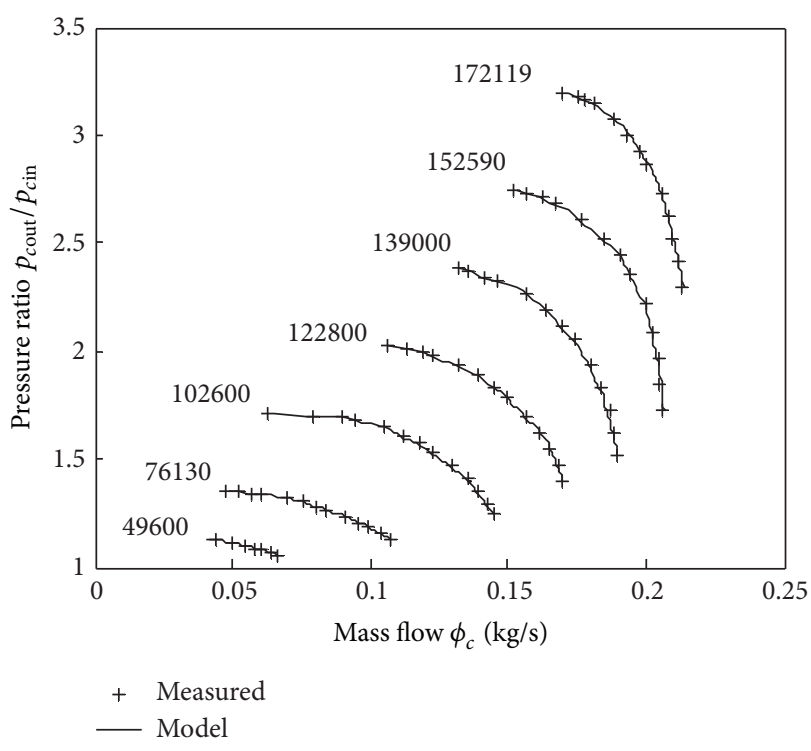

Figure 3: Mass flow model for compressor at stationary engine condition (the unit of compressor speed is rpm).

where $p_{c o u t}$ and $p_{\text {cin }}$ are the pressure out of compressor and into compressor, respectively, $T_{c \text { in }}$ is the temperature of air into compressor, $C_{p}$ is air heat capacity, and $\gamma_{c}$ is specific heat capacity ratio.

Combining (9) with (10), the mass flow $\phi_{c}$ through the compressor is derived:

$$
\Phi_{c}=k_{n 1} \omega_{t c}-k_{n 2} \sqrt{k_{n 3} \omega_{t c}^{2}+k_{n 4}\left[\left(\frac{p_{c o u t}}{p_{c \text { in }}}\right)^{1-1 / \gamma_{c}}-1\right]},
$$

where $k_{n 1}=2 \rho_{c} A_{c} \gamma_{c} \tan \beta_{c} /\left(2 \delta_{c}\left(\rho_{c} A_{c} \tan \beta_{c}\right)^{2}-1\right)$, $k_{n 2}=\rho_{c} A_{c} \gamma_{c} \tan \beta_{c} /\left(-2 \delta_{c}\left(\rho_{c} A_{c} \tan \beta_{c}\right)^{2}-1\right), k_{n 3}=$ $2 r_{c 2}^{2}-2\left(\rho_{c} A_{c} \tan \beta_{c}\right)^{2} \delta_{c} r_{c 1}^{2}+4\left(\rho_{c} A_{c} \tan \beta_{c}\right)^{2} \delta_{c} r_{c 2}^{2}$, and $k_{n 4}=$ $-2 C_{p} T_{c \text { in }}\left(\left(\rho_{c} A_{c} \tan \beta_{c}\right)^{2} \delta_{c}+1\right)$.

For all parameters of (11), only $\beta_{c}$ needs to be adjusted. This is different from other models. As shown in Figure 3, measured data of the mass flow agree with model simulation results accurately over the whole operating range. The average error is $0.12 \%$. Figure 4 shows the results of fine-tuned parameter $\beta_{c}$.

The efficiency of the compressor is defined as the ratio of isentropic to the actual total input work:

$$
\eta_{c}=\frac{h_{\text {total }}-h_{\text {inc }}-h_{\text {fric }}}{h_{\text {total }}} .
$$

Substituting (5), (6), and (7) into (12), the efficiency is rewritten as

$$
\eta_{c}=\frac{k_{c 1}}{\omega_{t c}^{2}} \phi_{c}^{2}+\frac{k_{c 2}}{\omega_{t c}} \phi_{c}+k_{c 3}
$$

where $k_{c 1}=\left(2 \delta_{c} \rho_{c} A_{c} \tan \beta_{c}-1\right) / 2\left(\rho_{c} A_{c} \tan \beta_{c}\right)^{2} r_{c 2}^{2}$ and $k_{c 2}=$ $r_{c 2} / r_{c 2}^{2} \rho_{c} A_{c} \tan \beta_{c}, k_{c 3}=1-\left(R_{c 2}^{2} / 2 r_{c 2}^{2}\right)$. 


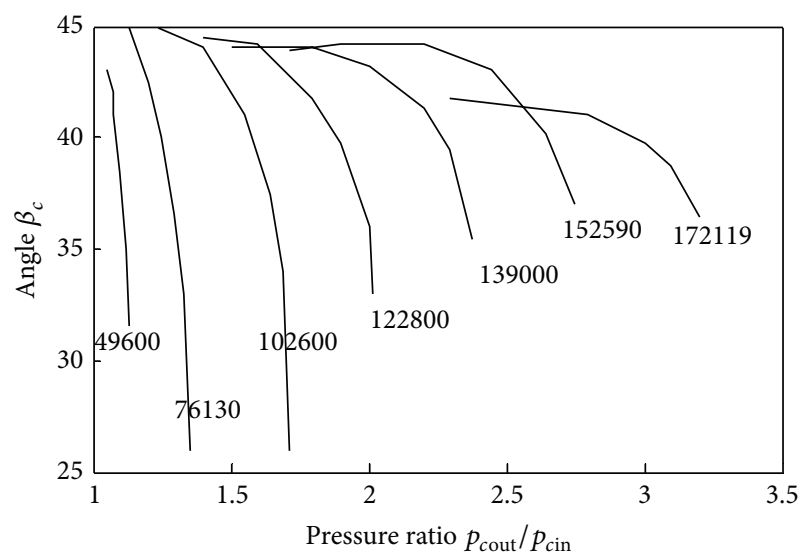

Figure 4: Optimal angle as parameter of compressor mass flow model (the unit of compressor speed is rpm).

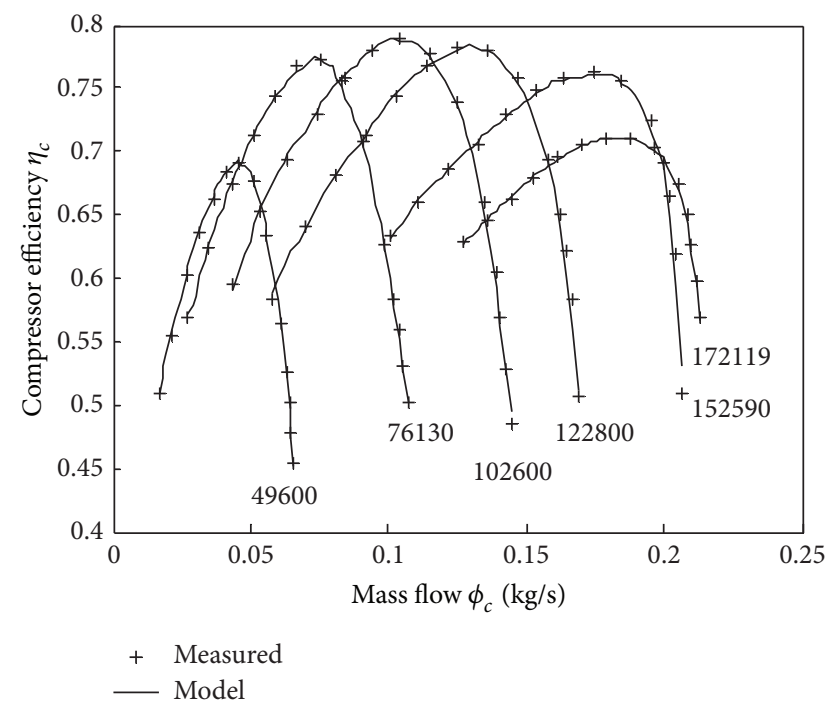

FIGURE 5: Efficiency model for compressor at stationary engine condition.

As shown in Figure 5, with the fine-tuned parameter $\beta_{c}$, measured data of the efficiency agree with model simulation results accurately over the whole operating range. Figure 6 shows the results of parameter $\beta_{c}$.

In addition, based on (13), compressor efficiency can also be modeled as a polynomial function, as shown in

$$
\begin{aligned}
\eta_{c}= & f_{(a 1, b 1, c 1, d 1)}\left(\frac{\phi_{c}}{\omega_{t c}}\right)^{4}+f_{(a 2, b 2, c 2, d 2)}\left(\frac{\phi_{c}}{\omega_{t c}}\right)^{3} \\
& +f_{(a 3, b 3, c 3, d 3)}\left(\frac{\phi_{c}}{\omega_{t c}}\right)^{2}+f_{(a 4, b 4, c 4, d 4)} \frac{\phi_{c}}{\omega_{t c}}+f_{(a 5, b 5, c 5, d 5)},
\end{aligned}
$$

where $f_{(a, b, c, d)}=a \omega_{t c}^{3}+b \omega_{t c}^{2}+c \omega_{t c}+d$.

The values of coefficients $a, b, c$, and $d$ are shown in Table 2.

Figures 7, 8, and 9 show the simulation and measured results. The maximum relative error is about $7 \%$ which

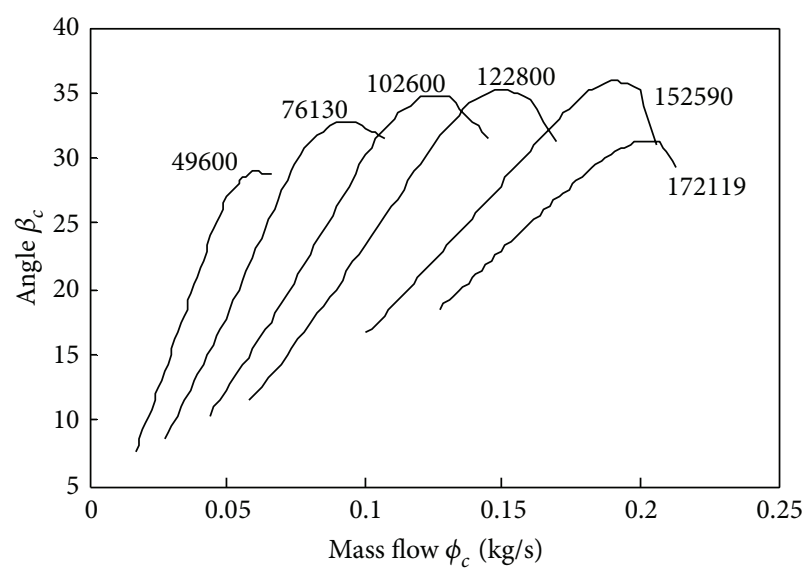

FIGURE 6: Optimal angle as parameter of compressor efficiency model.

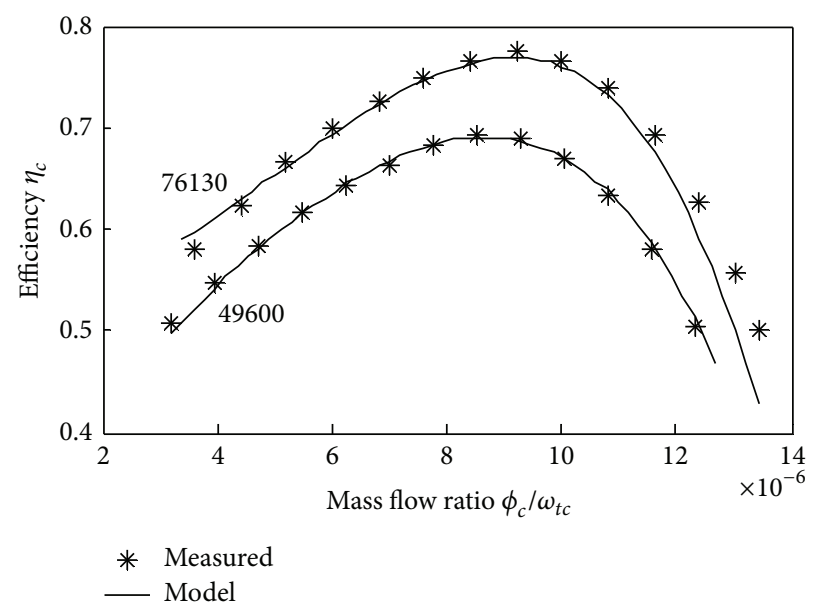

FIGURE 7: Efficiency model in polynomial form at stationary engine conditions (turbo speeds: $76130 \mathrm{rpm}$ and $49600 \mathrm{rpm}$ ).

TABLE 2: Coefficient values of function $f_{(a, b, c, d)}$.

\begin{tabular}{lcccc}
\hline & $a$ & $b$ & $c$ & $d$ \\
\hline$f_{(a 1, b 1, c 1, d 1)}$ & $-1.49 * 10^{6}$ & $2.66 * 10^{11}$ & $-1.58 * 10^{16}$ & $2.56 * 10^{20}$ \\
$f_{(a 2, b 2, c 2, d 2)}$ & 50.71 & $-8.53 * 10^{6}$ & $4.56 * 10^{11}$ & $-6.82 * 10^{15}$ \\
$f_{(a 3, b 3, c 3, d 3)}$ & $-6.75 * 10^{-4}$ & 111.88 & $-5.64 * 10^{6}$ & $7.52 * 10^{10}$ \\
$f_{(a 4, b 4, c 4, d 4)}$ & $4.15 * 10^{-9}$ & $-7.06 * 10^{-4}$ & 36.22 & $-4.52 * 10^{5}$ \\
$f_{(a 5, b 5, c 5, d 5)}$ & $-9.62 * 10^{-15}$ & $1.67 * 10^{-9}$ & $-8.62 * 10^{-5}$ & 1.55 \\
\hline
\end{tabular}

occurs at speeds of $172119 \mathrm{rpm}$ and $102600 \mathrm{rpm}$. For other compressor speeds, the relative error is less than $0.4 \%$.

3.2. Turbine. Turbine is driven by the exhaust gas to provide power for compressor. The turbine model consists of submodels for the turbine mass flow and the turbine efficiency.

Turbine mass flow is modeled as exhaust gas flowing through a nozzle $[11,12]$. In particular, the pressure ratio at chock $\mathrm{pr}_{\text {crit }}$ of turbine is much higher than that of an adiabatic nozzle. The choke pressure ratio of turbine is measured 


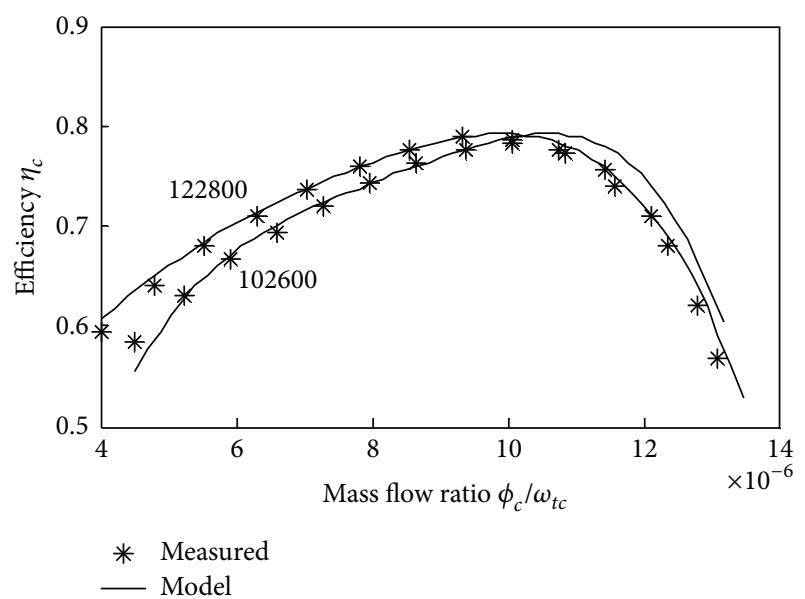

FIGURE 8: Efficiency model in polynomial form at stationary engine conditions (turbo speeds, $122800 \mathrm{rpm}$ and $102600 \mathrm{rpm}$ ).

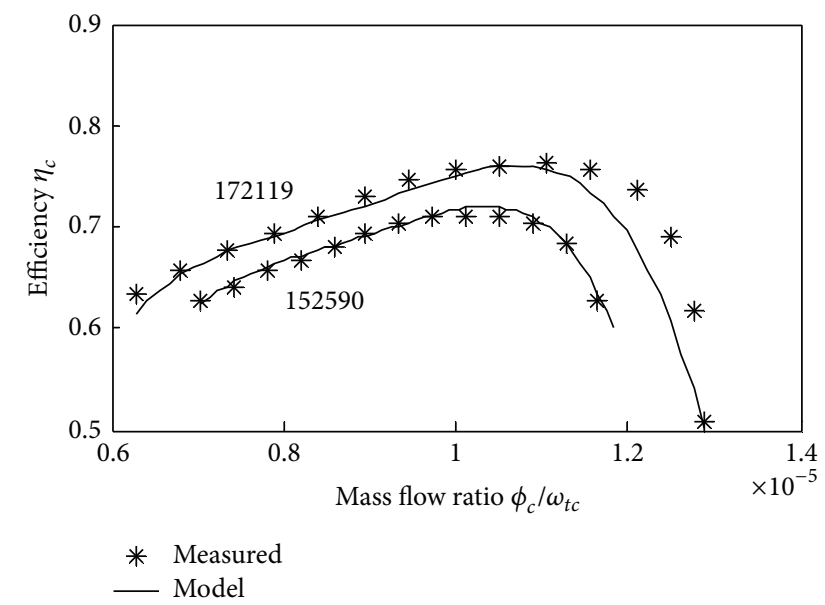

FIGURE 9: Efficiency model in polynomial form at stationary engine conditions (turbo speeds: $172119 \mathrm{rpm}$ and $152590 \mathrm{rpm}$ ).

through experiments. At the condition in which $p_{t o u t} / p_{\text {tin }}<$ $\mathrm{pr}_{\text {crit }}$, choke occurs, and the calculation formula of turbine mass flow is shown in (15). When $p_{\text {tout }} / p_{\text {tin }}>\mathrm{pr}_{\text {crit }}$, the calculation formula is shown in (16). In addition, turbine mass flow has a significant speed dependence, which is shown in Figure 10. Consider

$$
\begin{gathered}
\phi_{t b}=\frac{p_{\text {ic }}}{\sqrt{R T_{\text {tin }}}} A_{t} \sqrt{\frac{2 \gamma}{\gamma-1}\left[\left(\mathrm{pr}_{\text {crit }}\right)^{2 /(\gamma-1)}-\left(\mathrm{pr}_{\text {crit }}\right)^{(\gamma+1) /(\gamma-1)}\right]} \\
\phi_{t b}=\frac{p_{\text {tin }}}{\sqrt{R T_{\text {tin }}}} A_{t} \sqrt{\frac{2 \gamma}{\gamma-1}\left[\left(\frac{p_{\text {tout }}}{p_{\text {tin }}}\right)^{2 / \gamma}-\left(\frac{p_{\text {tout }}}{p_{\text {tin }}}\right)^{(\gamma+1) / \gamma}\right]},
\end{gathered}
$$

where $p_{\text {tin }}$ is the turbine entry pressure, $p_{\text {tout }}$ is the turbine exit pressure, $T_{\text {tin }}$ is the entry temperature of air, $\gamma=1.4$ is the specific heat capacity ratio, and $A_{t}$ is the effective
TABLE 3: Coefficient values of function $A_{t}$.

\begin{tabular}{lc}
\hline Coefficient & Value \\
\hline$a_{t m 1}$ & $3.32 * 10^{-13}$ \\
$b_{t m 1}$ & $-1.07 * 10^{-7}$ \\
$c_{t m 1}$ & 0.0101 \\
$a_{t m 2}$ & $-2.69 * 10^{-13}$ \\
$b_{t m 2}$ & $9.93 * 10^{-8}$ \\
$c_{t m 2}$ & -0.0044 \\
\hline
\end{tabular}

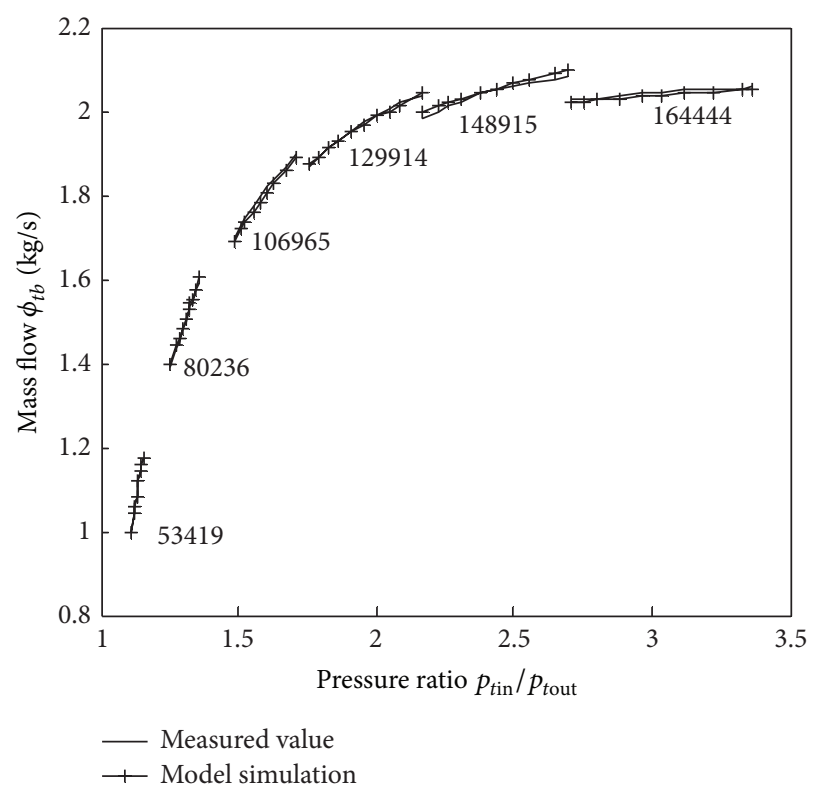

FIgURE 10: Turbine mass flow model.

cross-sectional area of turbine which varies with tangential component of velocity. $A_{t}$ is given by

$$
\begin{aligned}
A_{t}= & \left(a_{t m 1} n_{t c}^{2}+b_{t m 1} n_{t c}+c_{t m 1}\right) \frac{p_{t \text { in }}}{p_{t \text { out }}} \\
& +\left(a_{t m 2} n_{t c}^{2}+b_{t m 2} n_{t c}+c_{t m 2}\right)
\end{aligned}
$$

where $n_{t c}$ is the turbine revolution speed (in units of revolutions per minute) and $a_{t m 1}, b_{t m 1}, c_{t m 1}, a_{t m 2}, b_{t m 2}$, and $c_{t m 2}$ are coefficients, whose values are shown in Table 3.

Measured and model simulation values of turbine mass flow for different speed are shown in Figure 10. The average error is $0.16 \%$.

Blade speed ratio (BSR) [11] is defined as the ratio of speed at the mean blade height $\left(U_{t}\right)$ to the velocity. The velocity is calculated assuming isentropic expansion from the inlet conditions to the pressure at the exit from the turbine (total to static). The function is given by

$$
\mathrm{BSR}=\frac{U_{t}}{\sqrt{2 c_{p} T_{\text {tin }}\left[1-\left(p_{\text {tout }} / p_{\text {tin }}\right)^{(\gamma-1) / \gamma}\right]}} .
$$


TABLE 4: Coefficient values of function $\eta_{t b}$.

\begin{tabular}{lc}
\hline Coefficient & Value \\
\hline$a_{t e 1}$ & $-1.74 * 10^{-14}$ \\
$b_{t e 1}$ & $4.16 * 10^{-9}$ \\
$c_{t e 1}$ & $-2.64 * 10^{-4}$ \\
$d_{t e 1}$ & -1.9538 \\
$a_{t e 2}$ & $2.99 * 10^{-14}$ \\
$b_{t e 2}$ & $-7.33 * 10^{-9}$ \\
$c_{t e 2}$ & $4.97 * 10^{-4}$ \\
$d_{t e 2}$ & 0.2828 \\
$a_{t e 3}$ & $-1.32 * 10^{-14}$ \\
$b_{t e 3}$ & $3.33 * 10^{-9}$ \\
$c_{t e 3}$ & $-2.43 * 10^{-4}$ \\
$d_{t e 3}$ & 2.1765 \\
\hline
\end{tabular}

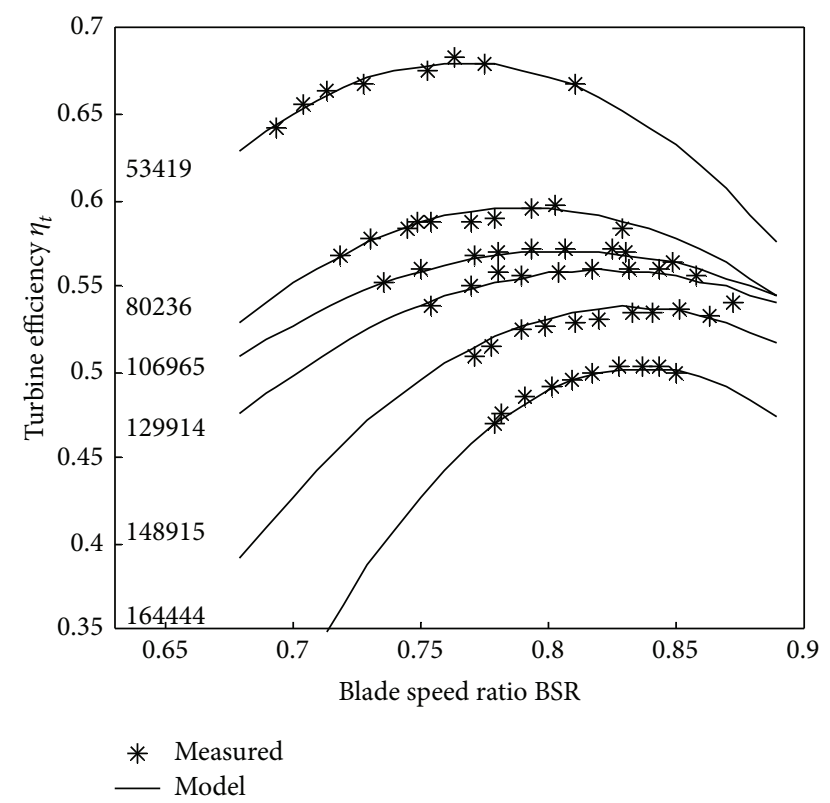

FIGURE 11: Turbine efficiency model.

Turbine efficiency is modeled as a polynomial function:

$$
\begin{aligned}
\eta_{t b}= & \left(a_{t e 1} n_{t c}^{3}+b_{t e 1} n_{t c}^{2}+c_{t e 1} n_{t c}+d_{t e 1}\right) \mathrm{BSR}^{2} \\
& +\left(a_{t e 2} n_{t c}^{3}+b_{t e 2} n_{t c}^{2}+c_{t e 2} n_{t c}+d_{t e 2}\right) \mathrm{BSR} \\
& +\left(a_{t e 3} n_{t c}^{3}+b_{t e 3} n_{t c}^{2}+c_{t e 3} n_{t c}+d_{t e 3}\right)
\end{aligned}
$$

where $a_{i}, b_{i}, c_{i}$, and $d_{i}(i=t e 1, t e 2, t e 3)$ are coefficients, whose values are shown in Table 4.

The measured and simulation results are shown in Figure 11. The average error is $1.2 \%$.

3.3. Air Filter. The most important feature of the air filter is the pressure drop that it causes. Air filter is modeled as a simple tube. According to pressure drop calculation for a tube
[13], air filter model can be described by (20). This model for pressure drop is also utilized by [5]:

$$
\Delta P_{a f}=C_{a f} \frac{T_{a f} \phi_{a f}^{2}}{P_{a f}},
$$

where $\Delta P_{a f}$ is pressure drop, $C_{a f}$ is a coefficient which depends on Reynolds number $R_{e}$, length and diameter of air filter, and gas constant $R$, and $T_{a f}, P_{a f}$, and $\phi_{a f}$ are upstream temperature, pressure, and mass flow of incoming air, respectively.

3.4. Intercooler. In order to cool down the compressed intake air, increase its density, and decrease knock probability, an intercooler is used in the air path of the engine.

Cengel [13] described a method called the effectiveness number of transfer units (NTU) method for intercooler heat exchanger analysis. The method is based on a dimensionless parameter called the heat transfer effectiveness $\varepsilon$, defined as

$$
\varepsilon=\frac{T_{\mathrm{ic}, \text { in }}-T_{\mathrm{ic}, \text { out }}}{T_{\mathrm{ic}, \text { in }}-T_{\mathrm{cool}}}
$$

where $T_{\mathrm{ic} \text {,in }}$ is the temperature of hot air that enters into intercooler, $T_{\mathrm{ic} \text {,out }}$ is the temperature of cooled air that outflows intercooler, and $T_{\text {cool }}$ is the temperature of ambient air that blows towards intercooler. According to (21), the temperature of cooled air $T_{\mathrm{ic}, \text { out }}$ that flows out of intercooler is given by

$$
T_{\mathrm{ic}, \text { out }}=T_{\mathrm{ic}, \text { in }}-\varepsilon\left(T_{\mathrm{ic}, \text { in }}-T_{\text {cool }}\right) .
$$

A detailed derivation for calculating the heat transfer effectiveness $\varepsilon$ is presented in [13]. The final equations are shown below:

$$
\begin{gathered}
\varepsilon=1-\exp \left\{\frac{\mathrm{NTU}^{0.22}}{c}\left[\exp \left(-c \cdot \mathrm{NTU}^{0.78}\right)-1\right]\right\}, \\
\mathrm{NTU}=\frac{U \cdot A_{s}}{C_{p} \phi_{\mathrm{ic}}}, \\
c=\frac{\phi_{\text {ic }}}{\phi_{\text {cool }}},
\end{gathered}
$$

where $U$ is the overall heat transfer coefficient, $A_{s}$ is the intercooler surface area, $C_{p}$ is air heat capacity, $\phi_{\text {ic }}$ is the mass of compressed air from compressor, and $\phi_{\text {cool }}$ is the mass of ambient air.

The advantage of NTU is that the model includes heat transfer physics. However, it is not accurate enough and the calculation of $\varepsilon$ is complex. Based on measured data, Eriksson [14] developed a regression model for the calculation of $\varepsilon$

$$
\varepsilon=a_{0}+a_{1}\left(\frac{T_{\mathrm{ic}, \text { in }}+T_{\mathrm{cool}}}{2}\right)+a_{2} \phi_{\mathrm{ic}}+a_{3} \frac{\phi_{\mathrm{ic}}}{\phi_{\mathrm{cool}}} .
$$

It is assumed that there is no pressure loss for intercooler, which gives the following equation:

$$
P_{\text {ic }, \text { out }}=P_{\text {ic,in }} \text {. }
$$


TABLE 5: Coefficient values of the effective opening area.

\begin{tabular}{lccc}
\hline Coefficient & $a_{\text {th2 }}$ & $a_{\text {th1 }}$ & $a_{\text {th0 }}$ \\
\hline Value & -0.1514 & 0.7816 & 0.1635 \\
\hline
\end{tabular}

3.5. Throttle. The throttle controls the amount of air flowing into cylinders in SI engine at part load. The butterfly type throttle is regarded as a nozzle with compressible gas flow. Heywood [15] described the model for the nozzle and [14, 16] used this method to develop the throttle model. Formulae are presented below.

When the gas velocity flowing through the throat of throttle is equal to or larger than the velocity of sound, that is, $p_{\text {imf }} / p_{\text {ic }}<(2 /(\gamma+1))^{\gamma /(\gamma-1)}$, the maximum mass flow occurs. The formula of calculating mass flow $\phi_{\mathrm{th}}$ is shown in

$$
\begin{aligned}
\phi_{\text {th }}= & C_{d} A_{\text {th }} \frac{p_{\text {ic }}}{\sqrt{R T_{\text {ic,out }}}} \\
& \cdot \sqrt{\frac{2 \gamma}{\gamma-1}\left[\left(\frac{2}{\gamma+1}\right)^{2 /(\gamma-1)}-\left(\frac{2}{\gamma+1}\right)^{(\gamma+1) /(\gamma-1)}\right]} .
\end{aligned}
$$

When the gas velocity is less than the velocity of sound, the formula of calculating mass flow is shown in

$\phi_{\mathrm{th}}=C_{d} A_{\mathrm{th}} \frac{p_{\mathrm{ic}}}{\sqrt{R T_{\mathrm{ic}, \mathrm{out}}}} \sqrt{\frac{2 \gamma}{\gamma-1}\left[\left(\frac{p_{\mathrm{imf}}}{p_{\mathrm{ic}}}\right)^{2 / \gamma}-\left(\frac{p_{\mathrm{imf}}}{p_{\mathrm{ic}}}\right)^{(\gamma+1) / \gamma}\right]}$,

where $A_{\text {th }}$ is the throttle plate opening area, $C_{d}$ is the discharge coefficient, $p_{\text {imf }}$ is the air pressure in intake manifold, and $\gamma=1.4$ is the specific heat capacity ratio. The effective opening area $C_{d} A_{\text {th }}$ is a function of throttle opening angle $\alpha$. The function is shown below:

$$
C_{d} A_{\mathrm{th}}=A_{1}\left(1-\cos \left(a_{\mathrm{th} 2} \alpha^{2}+a_{\mathrm{th} 1} \alpha+a_{\mathrm{th} 0}\right)\right)+A_{0},
$$

where $A_{1}$ is the throttle bore area, $A_{0}$ is leakage area, and $a_{\mathrm{th} 2}, a_{\mathrm{th} 1}$, and $a_{\mathrm{th} 0}$ are fit coefficients based on measured data, whose values are shown in Table 5.

Model simulation results versus measured values of effective area are shown in Figure 12 and results of mass flow through throttle are shown in Figure 13. The models capture the main characters of effective area and mass flow through throttle.

3.6. Manifold. For the intake and exhaust manifolds, pressure in manifold depends on the change rate of the total air mass, which is equal to the sum of the air mass flows into and out of the manifold. Manifold models can be created according to

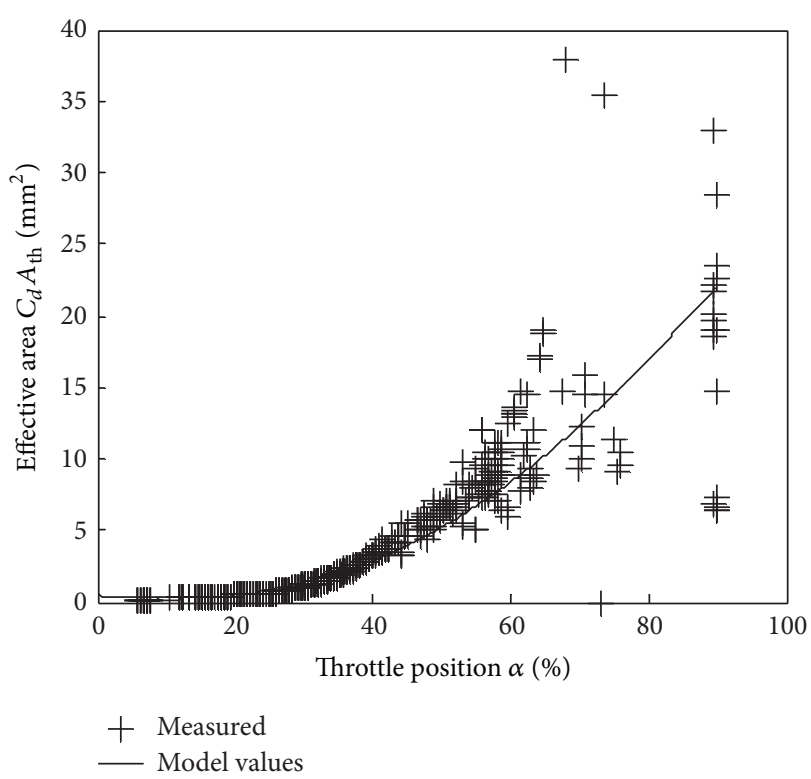

FIGURE 12: Effective area of throttle.

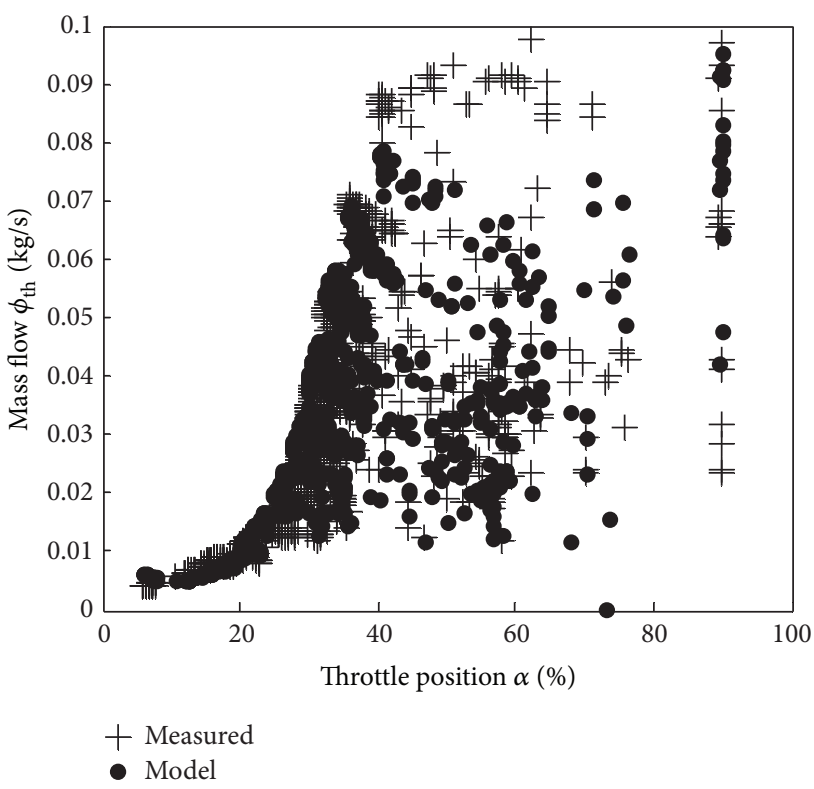

Figure 13: Air mass flow through throttle.

isothermal model $[15,17]$. The intake and exhaust manifolds are modeled as follows:

$$
\begin{gathered}
\frac{d p_{\mathrm{imf}}}{d t}=\frac{R_{a} T_{\mathrm{imf}}}{V_{\mathrm{imf}}}\left(\phi_{\mathrm{th}}-\phi_{\text {ein }}\right) \\
\frac{d p_{\mathrm{emf}}}{d t}=\frac{R T_{\mathrm{emf}}}{V_{\mathrm{emf}}}\left(\phi_{\text {eout }}-\phi_{t b}\right),
\end{gathered}
$$

where $p_{\mathrm{imf}}$ and $p_{\mathrm{emf}}$ are the pressure of intake and exhaust manifolds, respectively, $T_{\mathrm{imf}}$ is the temperature of air flowing into intake manifold, which is assumed to be equal to the temperature of cooled air that exits intercooler, $T_{\mathrm{emf}}$ is the temperature of exhaust manifold, $V_{\mathrm{imf}}$ and $V_{\mathrm{emf}}$ are volumes 


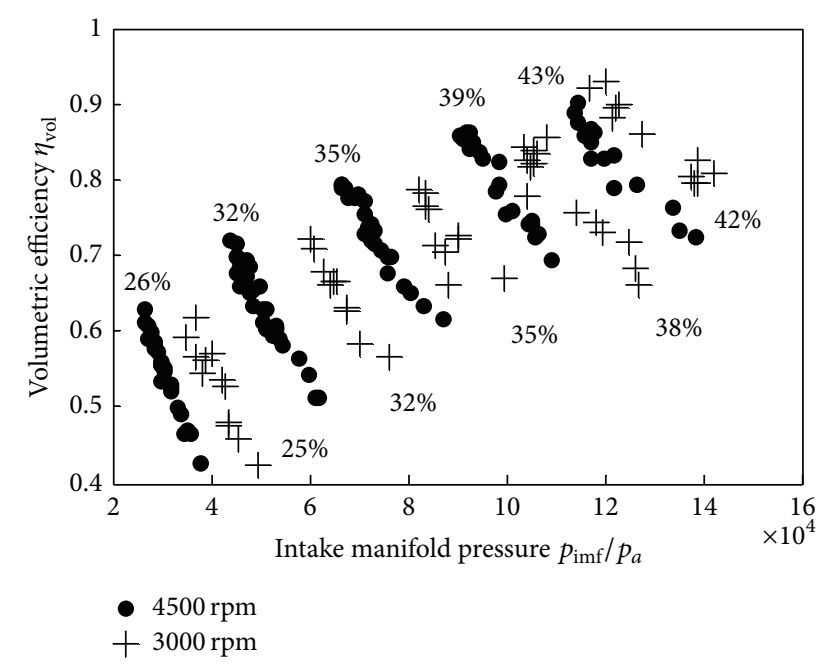

FIGURE 14: Volumetric efficiency for engine speeds $4500 \mathrm{rpm}$ and $3000 \mathrm{rpm}$.

of intake and exhaust manifolds, $\phi_{\text {ein }}$ is the mass flow from the intake manifold into the cylinders, and $\phi_{\text {eout }}$ is the total mass flow out from cylinder. The ideal gas constant $R_{a}$ of intake manifold and ideal gas constant $R$ of exhaust manifold are different because $T_{\text {emf }}$ is much higher than $T_{\text {imf }}$.

3.7. Cylinder. The total mass flow $\phi_{e i}$ into the cylinder is modeled using the standard model based on volumetric efficiency:

$$
\phi_{e i}=\frac{\eta_{\mathrm{vol}}\left(p_{\mathrm{imf}}, n_{e}, \alpha\right) p_{\mathrm{imf}} n_{e} V_{d}}{120 R_{a} T_{\mathrm{imf}}}
$$

where $p_{\text {imf }}$ is the air pressure in the intake manifold. $T_{\text {imf }}$ is the air temperature in the intake manifold, $n_{e}$ is engine speed, $V_{d}$ is displacement volume, and $\eta_{\mathrm{vol}}$ is volumetric efficiency which is a function of $p_{\mathrm{imf}}, n_{e}$, and throttle opening angle $\alpha . \eta_{\mathrm{vol}}$ is a function of engine speed, throttle position, and intake manifold pressure and the results are shown in Figures 14 and 15. For a given engine and throttle position, volumetric efficiency varies with intake manifold pressure as the cylinder intake and exhaust valve timings are changed. For example, in Figure 14, at the condition in which engine speed is equal to $4500 \mathrm{rpm}$ and throttle position is equal to $26 \%$, the volumetric efficiency varies from 0.63 to 0.42 .

The fuel mass flow $\phi_{e f}$ injected into cylinder varies with air fuel ratio. The fuel mass flow can be modeled [7] with fuel mass flow variable $\mu_{\delta}$ which has units of milligrams, engine speed $n_{e}$, and the number of cylinder $n_{\text {cyl }}$ :

$$
\phi_{e f}=\frac{10^{-6}}{120} \mu_{\delta} n_{e} n_{\mathrm{cyl}} .
$$

The mass flow out from the cylinder is the sum of the total mass flow into cylinders $\phi_{e i}$ and the fuel mass injected into cylinders $\phi_{e f}$.

For the engine torque $M_{e}$, based on the engine friction definition in reference [15], it can be calculated from gross

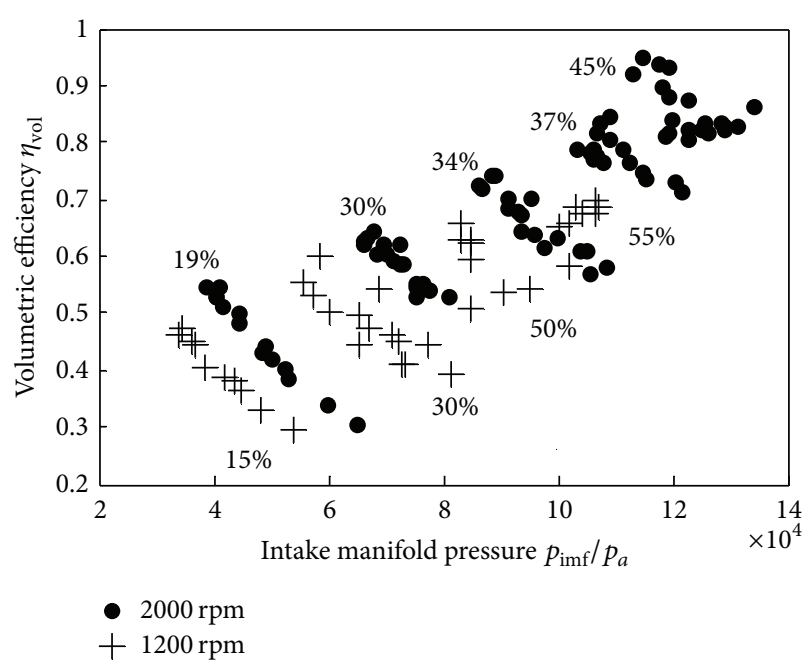

FIGURE 15: Volumetric efficiency for engine speeds $2000 \mathrm{rpm}$ and $1200 \mathrm{rpm}$.

indicated torque $M_{i g}$ and total friction torque $M_{t f}$. The total friction torque includes friction torques produced by pumping work, rubbing friction work, and accessory work. The engine toque is then

$$
M_{e}=M_{i g}-M_{t f} .
$$

The gross indicated torque is calculated from fuel consumption:

$$
M_{i g}=\frac{30 \phi_{e f} Q_{\mathrm{HV}} \eta_{i g}}{\pi n_{e}},
$$

where $\eta_{i g}=1-\left(1 / r_{c}^{\gamma-1}\right)$ (this assumes instantaneous adiabatic combustion at top dead center), where $r_{c}$ is the compression ratio and $\gamma$ is the specific heat capacity ratio, and $Q_{H V}$ is the fuel heating value.

The total friction torque of SI engine is modeled as a function of engine speed:

$$
M_{t f}=\frac{V_{d} 10^{5}}{4 \pi}\left(C_{f 1}+C_{f 2} \frac{n_{e}}{1000}+C_{f 3}\left(\frac{n_{e}}{1000}\right)^{2}\right) .
$$

Exhaust temperature $T_{\text {exh }}$ is important to model turbocharged engines. Models for exhaust temperature in reference [17] have two components, which are an exhaust manifold temperature and a temperature drop in a straight pipe.

The exhaust manifold temperature is modeled as

$$
T_{\mathrm{cyl}}=e^{a_{\mathrm{cy}}+\left(b_{\mathrm{cy}} / \phi_{\mathrm{exh}}\right)}
$$

where $T_{\text {cyl }}$ is temperature of the fluid delivered by the cylinder to the exhaust manifold, $\phi_{\text {exh }}$ is the exhaust mass flow, and $a_{\text {cy }}$ and $b_{\text {cy }}$ are tuning parameters, whose values are 7.239 and -0.005 , respectively.

The temperature at the turbine inlet is modeled as (36), which is based on temperature drop in a straight pipe:

$$
T_{\text {exh }}=T_{\text {amb }}+\left(T_{\text {cyl }}-T_{\text {amb }}\right) e^{-h_{c v} \pi d_{\text {pipe }} l_{\text {pipe }} / \phi_{\text {exh }} C_{p}},
$$




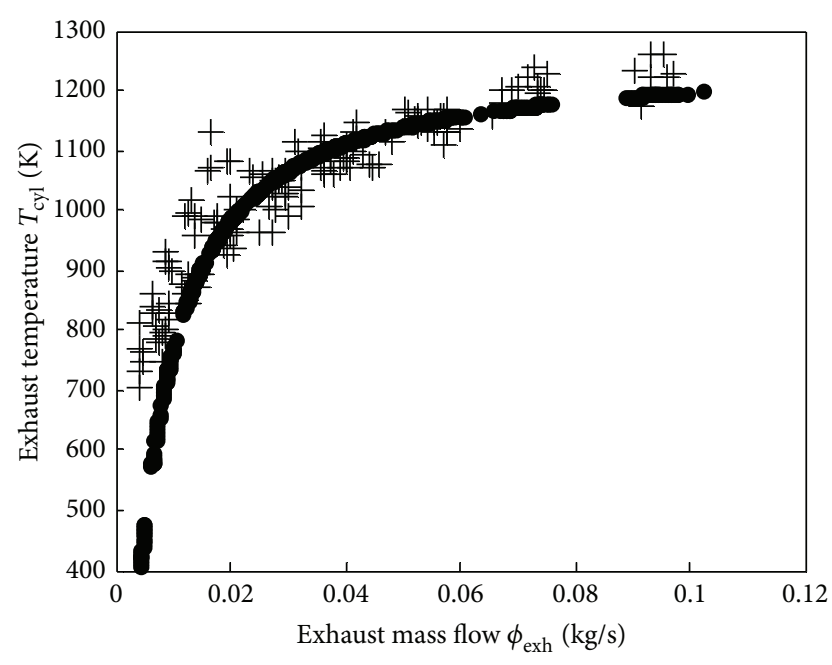

- Model

+ Measured

FIGURE 16: Model of the temperature at the turbine inlet.

where $T_{\mathrm{amb}}$ is the pipe wall temperature which is equal to ambient temperature, $h_{c v}$ is the total transfer coefficient, $d_{\text {pipe }}$ and $l_{\text {pipe }}$ are the diameter and length of exhaust pipe, respectively, and $C_{p}$ is the heat capacity. The model validated results are shown in Figure 16. $T_{\text {cyl }}$ is predicted utilizing (35) and the parameters of $T_{\text {cyl }}$ are tuned.

\section{Experiment and Simulation}

All engine models above are parameterized to experimental data that are collected on a $2.0 \mathrm{~L}$ four-cylinder turbocharged SIDI engine at steady state conditions. Sensors like incylinder pressure sensors, k-type thermocouples, and air flow meter are equipped on the test bench. The models are validated at engine speeds from 1000 RPM up to 4500 RPM.

The whole simulation models are implemented in Simulink according to the physical engine system, as shown in Figure 17. The parameters and coefficients of the models are listed in Section 3. The completed model includes intercooler, throttle, intake manifold, cylinder, air filter, compressor, turbo, turbine, and exhaust manifold.

The engine was operated at around $2200 \mathrm{r} / \mathrm{min}$ with gasoline 97\#. Figures 18 and 19 show the other engines' working conditions. The throttle position was stepped from $33.7 \%$ open to $45.5 \%$ open, after holding for 35 seconds, and then fell back to $38.4 \%$ open. The varying tendency of injection duration is almost the same.

In Figures 20-23, the simulated results are compared to the experimental measurements. The model is able to capture the transient dynamics and estimate the outputs with desirable accuracy. In Figure 20, the modeled intake mass flow results are a little ahead of experimental measurements at the rising phase. After that, the model retains its good tracking performance. The transient error is a result of the response time of the air mass flow transducer. In Figure 21, the model tracks the transient dynamics well at the rising

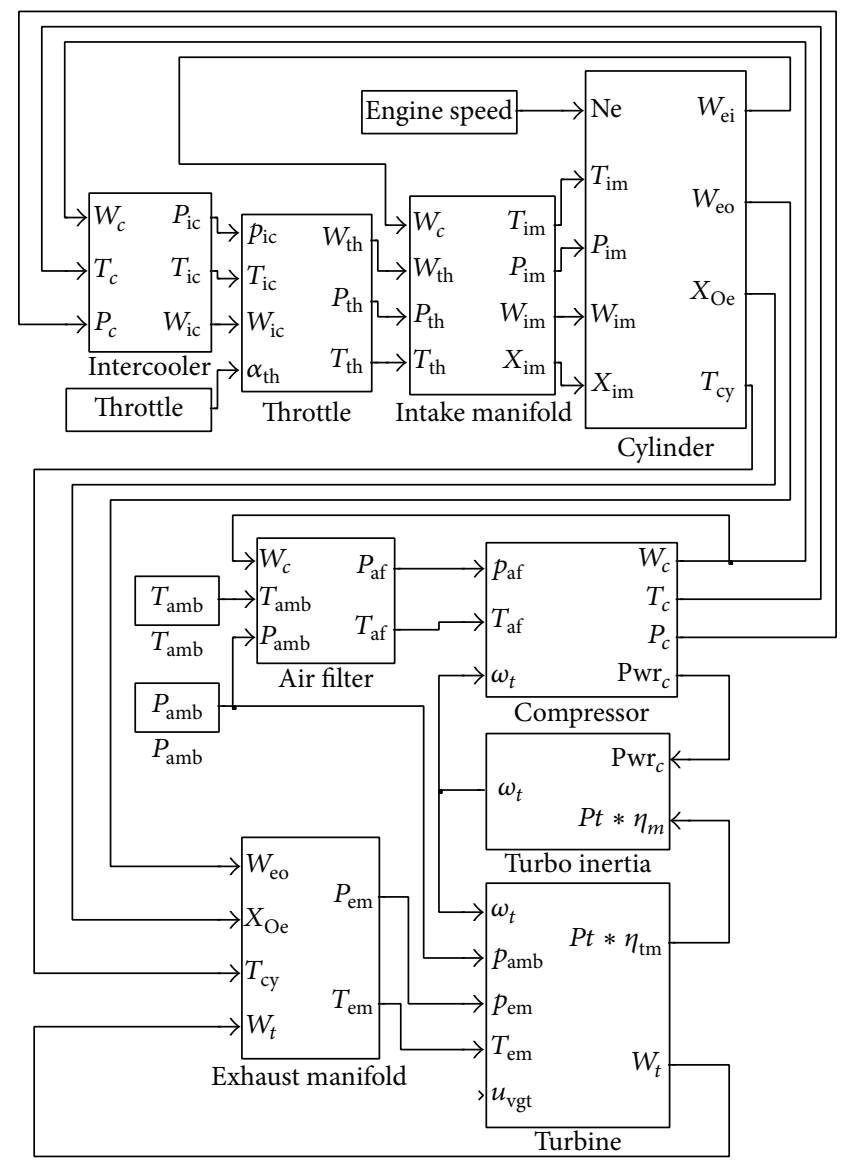

FIGURE 17: Complete control-oriented model.

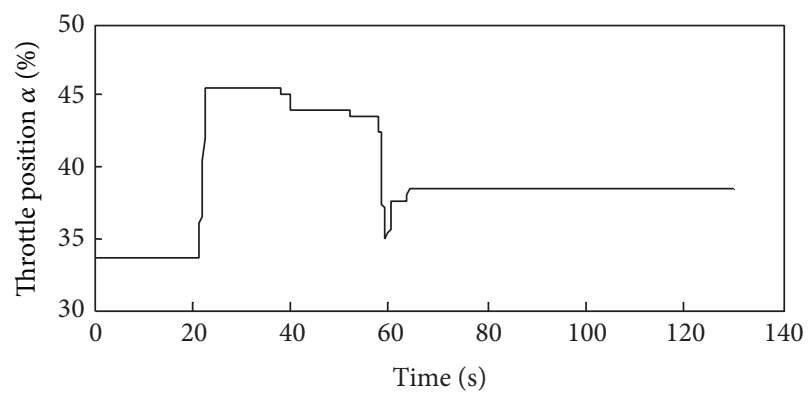

FIgURE 18: Throttle position of engine operation conditions.

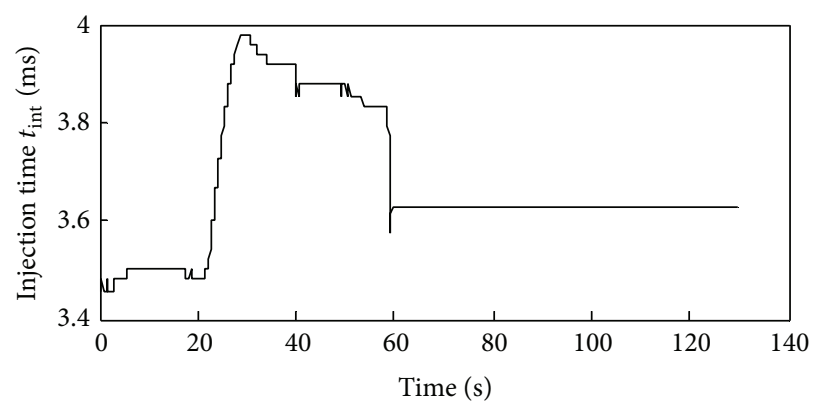

FIGURE 19: Injection duration of engine operation conditions. 


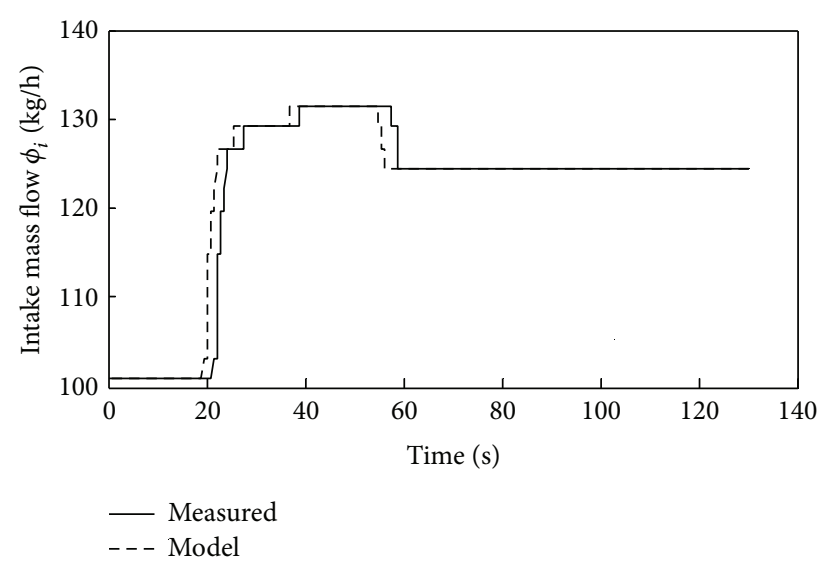

FIGURE 20: Measured and modeled results of intake air mass flow.

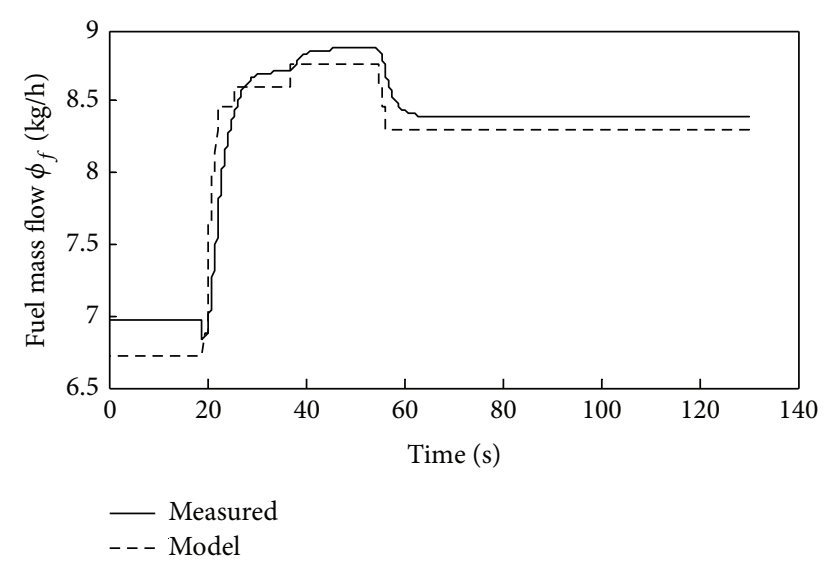

FIGURE 21: Measured and modeled results of fuel mass flow.

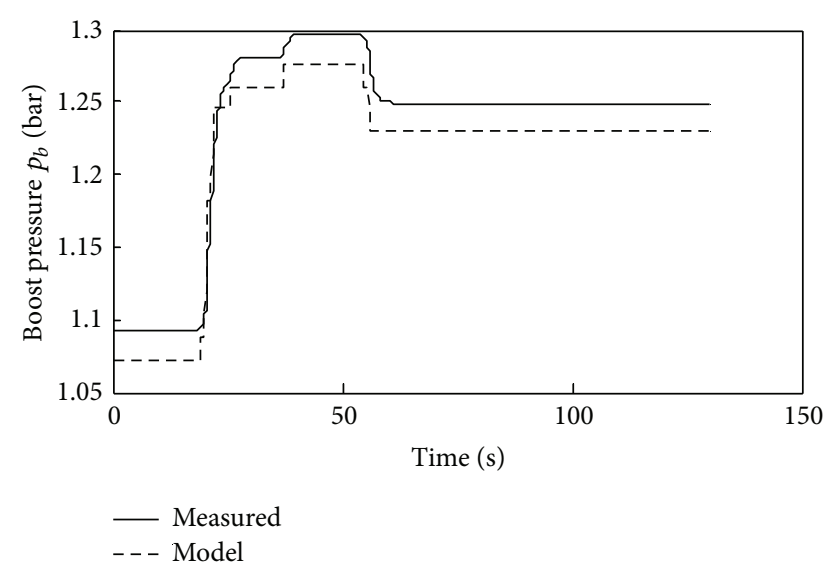

FIGURE 22: Measured and modeled results of boost pressure.

phase, but, in stable phase, the estimation error is 0.11 , about $1.3 \%$. The boost pressure and intake manifold pressure results shown in Figures 22 and 23 have the same characteristics with fuel mass flow.

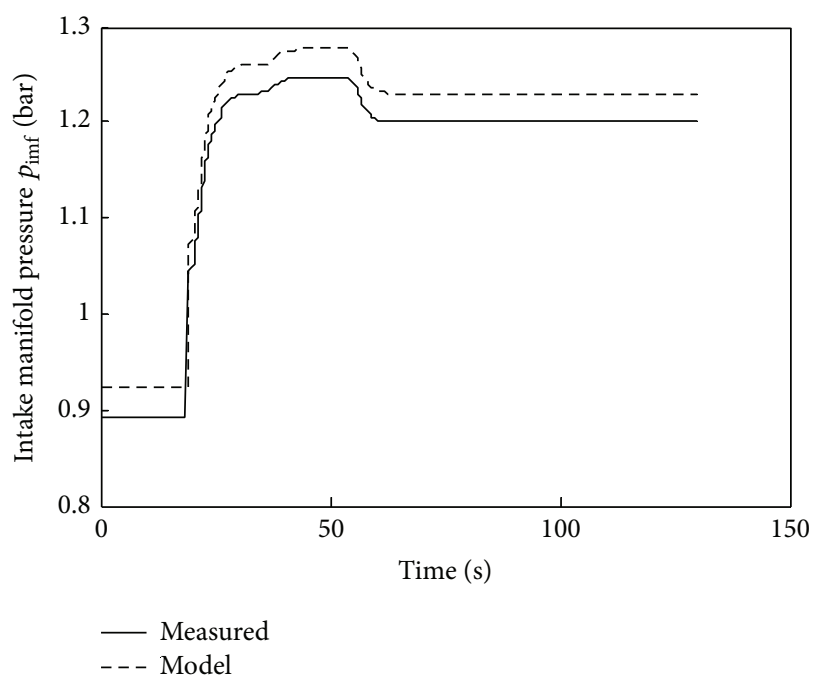

FIGURE 23: Measured and modeled results of intake manifold pressure.

\section{Conclusions}

A complete mean value model based on component submodels has been developed and validated. The intended applications of the models are developments of model-based control strategies and system analysis. Several submodels were described and novel models for compressor flow and compressor efficiency were developed. The accuracy of the new compressor model has an average error of $0.12 \%$, which is a significant improvement over conventional mapping approaches. The experimental results confirm that the developed model is capable of tracking transient dynamics. Compared to the conventional lookup table approach, our validation results show that transient dynamics error can be improved significantly through using the model from this work.

\section{Conflict of Interests}

The authors declare that there is no conflict of interests regarding the publication of this paper.

\section{Acknowledgments}

The authors would like to acknowledge Dr. Patrick Gorzelic of the University of Michigan (Ann Arbor) for the discussions and suggestions about the models. This project is supported by National Natural Science Foundation of China (no. 51475151), China Scholarship Council Foundation (no. 2012-3022), and Hunan University Young Teachers Sponsor Project.

\section{References}

[1] G. A. Lavoie, J. Martz, M. Wooldridge, and D. Assanis, "A multimode combustion diagram for spark assisted compression 
ignition," Combustion and Flame, vol. 157, no. 6, pp. 1106-1110, 2010.

[2] P. Gorzelic, P. Shingne, J. Martz, and G. A. Stefanopoulou, "A low-order HCCI model extended to capture SI-HCCI mode transition data with two-stage cam switching," in Proceedings of the ASME Dynamic Systems and Control Conference, San Antonio, Tex, USA, October 2014.

[3] E. Hellstrom, J. Larimore, S. Jade, A. G. Stefanopoulou, and L. Jiang, "Reducing cyclic variability while regulating combustion phasing in a four-cylinder HCCI engine," IEEE Transactions on Control Systems Technology, vol. 22, no. 3, pp. 1190-1197, 2014.

[4] P. Moraal and I. Kolmanovsky, "Turbocharger modeling for automotive control applications," in Proceedings of the SAE World Congress \& Exhibition, Detroit, Mich, USA, March 1999.

[5] L. Eriksson, "Modeling and control of turbocharged SI and DI engines," Oil \& Gas Science and Technology, vol. 62, no. 4, pp. 523-538, 2007.

[6] L. Kocher, E. Koeberlein, K. Stricker, D. G. van Alstine, B. Biller, and G. M. Shaver, "Control-oriented modeling of diesel engine gas exchange," in Proceedings of the American Control Conference (ACC '11), pp. 1555-1560, San Francisco, Calif, USA, June-July 2011.

[7] M. Taburri, F. Chiara, M. Canova, and Y.-Y. Wang, "A modelbased methodology to predict the compressor behaviour for the simulation of turbocharged engines," Proceedings of the Institution of Mechanical Engineers, Part D: Journal of Automobile Engineering, vol. 226, no. 4, pp. 560-574, 2012.

[8] M. Santillo and A. Karnik, "Model Predictive Controller design for throttle and wastegate control of a turbocharged engine," in Proceedings of the American Control Conference (ACC '13), pp. 2183-2188, IEEE, Washington, DC, USA, June 2013.

[9] D. Malkhede and B. Seth, "State feedback speed controller for turbocharged diesel engine and its robustness," World Academy of Science, Engineering and Technology, vol. 75, pp. 119-125, 2013.

[10] R. Salehi, M. Shahbakhti, A. Alasty, and G. R. Vossoughi, "Control oriented modeling of a radial turbine for a turbocharged gasoline engine," in Proceedings of the American Control Conference (ACC '13), pp. 5207-5212, Washington, DC, USA, June 2013.

[11] N. Watson and M. S. Janota, Turbocharging the Internal Combustion Engine, Macmillan, Basingstoke, UK, 1982.

[12] P. Moraal and I. Kolmanovsky, "Turbocharger modeling for automotive control applications," in Proceedings of the SAE International Congress \& Exposition, Paper no. 1999-01-0908, pp. 1-14, Detroit, Mich, USA, March 1999.

[13] Y. A. Cengel, Heat Transfer: A Practical Approach, McGraw-Hill, New York, NY, USA, 2002.

[14] L. Eriksson, L. Nielsen, J. Brugård, J. Bergström, F. Pettersson, and P. Andersson, "Modeling of a turbocharged SI engine," Annual Reviews in Control, vol. 26, no. 1, pp. 129-137, 2002.

[15] J. B. Heywood, Internal Combustion Engine Fundamentals, McGraw-Hill, New York, NY, USA, 1988.

[16] M. Nyberg and L. Nielsen, "Model based diagnosis for the air intake system of the SI-engine," in Proceedings of the SAE International Congress \& Exposition, Paper no. 970209, Detroit, Mich, USA, February 1997.

[17] L. Eriksson, "Mean value models for exhaust system temperature," in Proceedings of the SAE World Congress \& Exhibition, Paper no. 2002-01-0374, Detroit, Mich, USA, March 2002. 

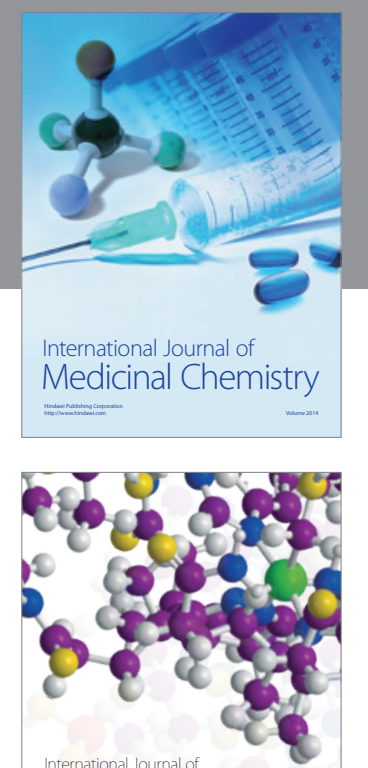

\section{Carbohydrate} Chemistry

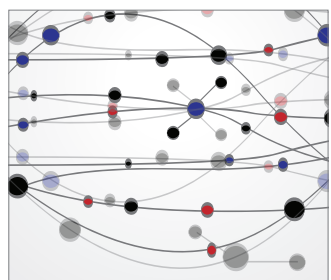

The Scientific World Journal
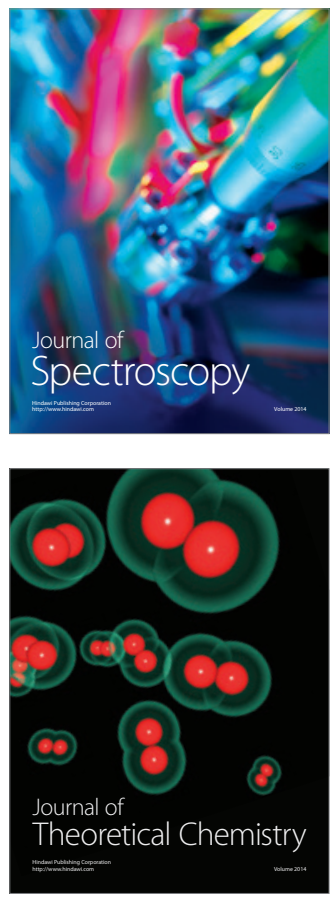
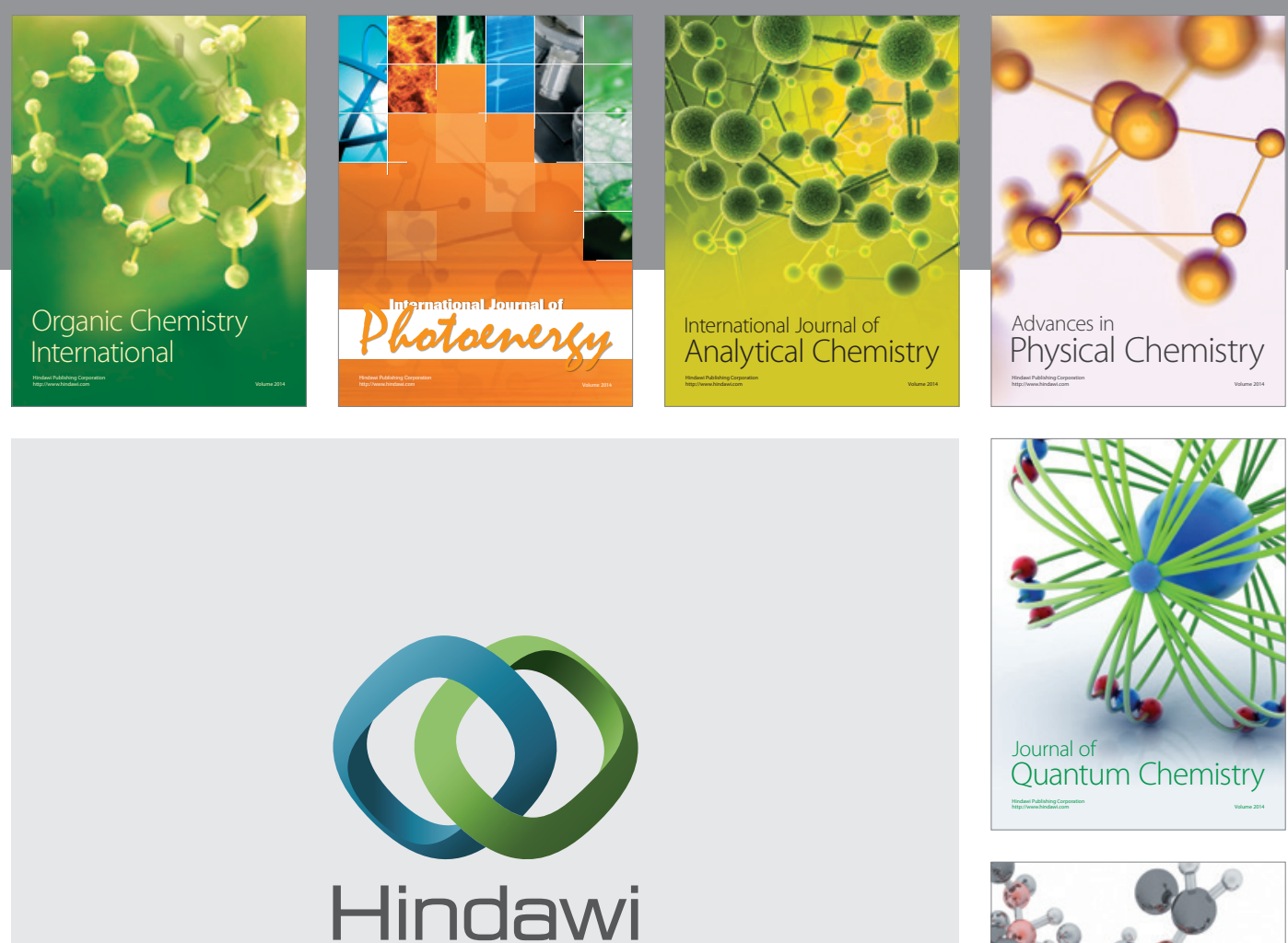

Submit your manuscripts at

http://www.hindawi.com

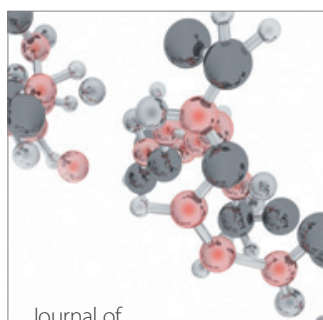

Analytical Methods

in Chemistry

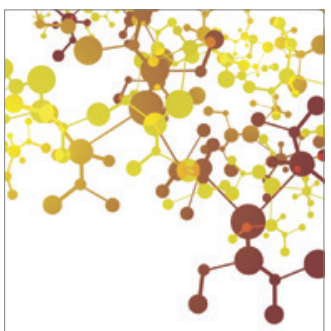

Journal of

Applied Chemistry

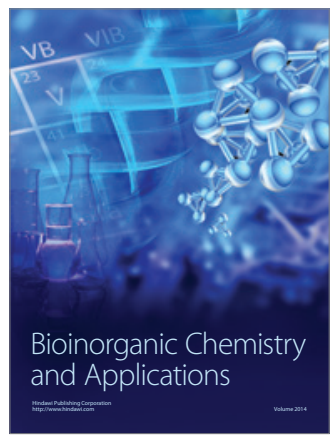

Inorganic Chemistry
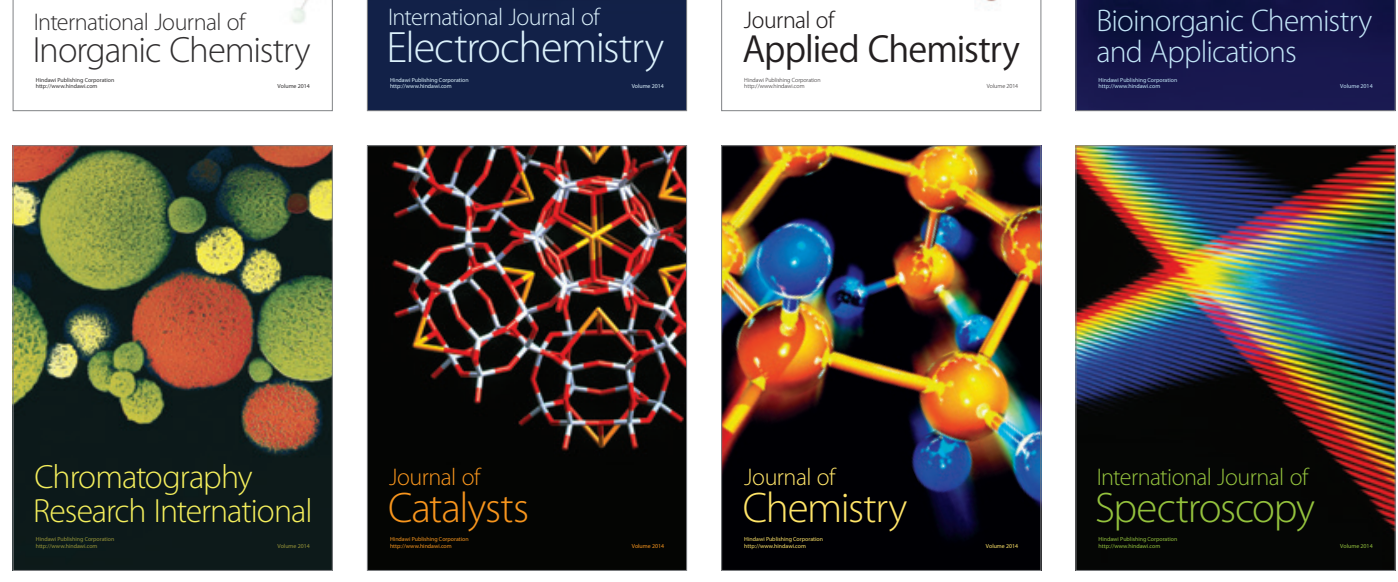